\title{
The SARS-CoV-2 virus
}

\author{
Frida Sommer ${ }^{1}$ and Ernesto Llamas ${ }^{2}$ \\ ${ }^{1}$ Affiliation not available \\ ${ }^{2}$ Journal of Sketching Science
}

February 23, 2021

\begin{abstract}
Viruses are non-living particles containing genetic information in the form of DNA or RNA. They are fascinating because they are not considered a form of life even though they evolve in the same way all living organisms do. Viruses are so-called obligate pathogens because they cannot multiply unless they infect and hijack the cellular machinery in living organisms.

The causative agent of the ongoing pandemic, the SARS-CoV-2, is a viral particle with a diameter between 50-200 nanometers and a simple architecture consisting essentially of four structural proteins. The nucleocapsid $(\mathrm{N})$ protein holds the viral RNA together inside the particle. The spike protein (S), envelope $(\mathrm{E})$, and membrane $(\mathrm{M})$ proteins form the viral envelope that protects the genetic material (Chang et al., 2014). Currently, most COVID-19 testing is performed using viral RNA extraction followed by RT-qPCR to amplify the genes of some of the above-mentioned proteins (Chu et al., 2020; Corman et al., 2020).
\end{abstract}




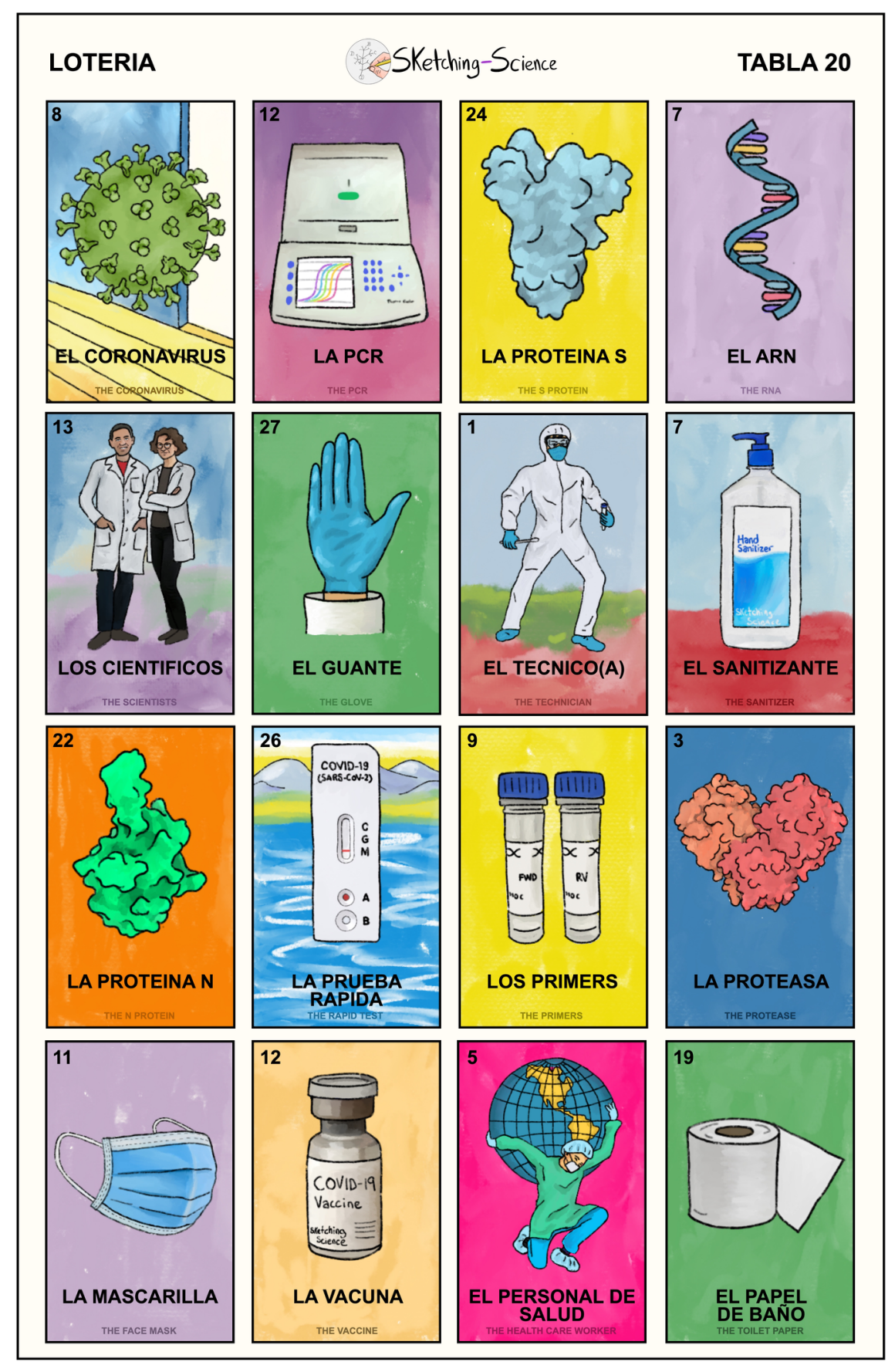

Figure 1: LOTERIA CORONAVIRUS. The illustration is based on the Mexican game Loteria (game similar to bingo).

Different mechanisms allow viruses to enter our cells. By mimicking host molecules, viruses gain entry into cells and evade the immune response. The S-protein of SARS-CoV-2 can bind to the human angiotensinconverting enzyme 2 (ACE2) by wearing the disguise of a particular epithelial sodium channel (ENaC- $\alpha$ ) in humans (Yan et al., 2020; Lan et al., 2020). To exert its function, ENaC- $\alpha$ binds to ACE2 and is 
recognized and cut by a specialized protein called transmembrane protease serine 2 (TMPRSS2). The site at which TMPRSS2 cuts ENaC- $\alpha$ is identical to a small part of the S-protein of SARS-CoV-2. Given the high structural similarity between the S-protein and our own ENaC- $\alpha$, both the ACE2 and TMPRSS2 cannot discriminate between the virus and our molecules and allows viral particles to enter our cells (Anand et al., 2020; Vkovski et al., 2020).

Once inside our cells, the viral particle disassembles and releases its RNA. The viral RNA serves as a manual for our ribosomes to produce the components required to generate more viral particles. The first viral protein that our cells synthesize is called replicase, and it makes thousands of copies of the viral RNA. These thousands of viral RNA copies are used to produce more viral components and assemble thousands of new viral particles that will be released by the infected cell upon its death. The newly generated viruses are ready to infect thousands of cells and start a new cycle of infection, replication, and dissemination (El Pais -Así infecta el coronavirus, 2020; COVID-19 Animation, n.d.).

A potential therapy against SARS-CoV-2 could aim at interfering with the binding of the S- protein to ACE2, thereby preventing the virus from entering our cells. This could be achieved by designing small peptides that can bind to the S-protein. During an active SARS-CoV-2 infection, these small peptides would bind the viral particle hiding the part of the S-protein that interacts with ACE2, effectively limiting the number of infected cells and slowing down the infection.

Although SARS-CoV-2 initially infects the respiratory tract, and lung cells, the ACE2 protein is expressed by cells from the heart, kidneys, and intestine. COVID-19 was initially described as a respiratory disease. However, as we advanced our knowledge of the virus's fundamental interactions with our cells, we learned that this disease affects multiple organs and cell types. To develop efficient therapies and vaccines against SARS-CoV-2, we need to better understand the origins of the virus, characterize the structure of its proteins and the function of its genes, and deepen our understanding of how it affects us. Drawing a clear and comprehensive picture of SARS-CoV-2 will reveal its strengths and weaknesses and provide us with the information needed to design effective therapies in the future. On the other hand, as a result of many years of fundamental research, some of the new vaccines against COVID-19 are showing impressive efficacy and are helping to control the current pandemic. Therefore, supporting fundamental research remains crucial for granting scientific progress in the future.

\section{Contributions}

- Frida Sommer wrote the article. She is a scientific editor and a freelance science writer (https: //www.vasocosmico.com/). She obtained her Ph.D. in immunology from Leiden University in the Netherlands and holds an MSc degree in archaeological sciences from Durham University. Her interests are very diverse. (https://www.linkedin.com/in/fridasommer/)

- Ernesto Llamas wrote/edited the article and made the illustration. He is currently a postdoctoral researcher at CECAD in Cologne, Germany. He obtained his Ph.D. in Biotechnology from Universitat de Barcelona doing his research at the Centre for Research in Agricultural Genomics. Creator, editor, and illustrator of Sketching Science. (Twitter@neto_flames; Instagram @eellamas).

\section{El virus SARS-CoV-2}

Los virus son microorganismos que no están vivos pero que contienen información genética en forma de ADN o ARN. Son fascinantes porque no se consideran una forma de vida a pesar de estar sujetos a los mismos procesos evolutivos que todos los seres vivos. Los virus son patógenos obligados porque no tienen los componentes necesarios para multiplicarse y necesariamente tiene que infectar y secuestrar la maquinaria 
celular de los organismos vivos (hospederos). El agente causante de la actual pandemia, el SARS-CoV-2, es un virus con un diámetro de entre 50 y 200 nanómetros y una arquitectura simple que consta de cuatro proteínas estructurales. La proteína de nucleocápside $(\mathrm{N})$ condensa el ARN viral. La proteína de pico o "spike" (S), la proteína de envoltura (E) y la de membrana (M) forman la envoltura viral que protege el material genético (Chang et al., 2014). Actualmente, la mayoría de las pruebas de COVID-19 se realizan mediante la extracción del ARN viral seguida de una RT-qPCR para amplificar los genes de algunas de estas proteínas (Chu et al., 2020; Corman et al., 2020).

Los virus cuentan con diferentes mecanismos que les permiten entrar a nuestras células. Uno de los más comunes es "disfrazarse" con moléculas muy parecidas a las del hospedero, de tal forma que virus ingresan a las células sin que la respuesta inmune lo reconozca como un agente extraño. Este es el caso de la proteína $\mathrm{S}$ del SARS-CoV-2 que puede unirse a la enzima convertidora de angiotensina humana 2 (ACE2), por ser muy parecida a un canal de sodio epitelial $(\mathrm{ENaC}-\alpha)$ de los humanos (Yan 2020, Lan 2020). Para ejercer su función, $\mathrm{ENaC}-\alpha$ se une a ACE2 para que una proteína especializada, llamada proteasa transmembrana serina 2 (TMPRSS2) rompe a ENaC- $\alpha$ de una forma específica. El sitio en el que TMPRSS2 parte a ENaC- $\alpha$ es idéntico a una pequeña parte de la proteína S del SARS-CoV-2. Es por esta altísima similitud estructural entre la proteína $\mathrm{S}$ y nuestra propia ENaC- $\alpha$ que ACE2 y TMPRSS2 no pueden discriminar entre el virus y nuestras propias proteínas, permitiendo así que las partículas virales entren en nuestras células (Anand et al., 2020; Vkovski et al., 2020).

Una vez dentro de nuestras células, la partícula viral se desensambla y libera su ARN. El ARN viral sirve como manual para que nuestros ribosomas produzcan los componentes necesarios para generar proteínas del virus. La primera proteína viral que sintetizan nuestras células se llama replicasa y produce miles de copias del ARN viral. Estas miles de copias de ARN viral se utilizan para producir más componentes virales y ensamblar miles de nuevas partículas virales que nuestras células liberan cuando mueren a causa de la infección. Estos nuevos virus pueden infectar miles de células del organismo e iniciar un nuevo ciclo de infección, multiplicación y diseminación (El País -Así infecta el coronavirus, 2020; COVID-19 Animation, n.d.).

Una opción terapéutica contra el SARS-CoV-2 podría tener como objetivo interferir con la unión de las proteínas S y ACE2, evitando así que el virus entre en nuestras células. Esto podría lograrse diseñando pequeños péptidos (o moléculas de otro tipo) que se unan a la proteína $\mathrm{S}$ de los virus que todavía no infectan nuestras células. Durante una infección activa por SARS-CoV-2, estas moléculas se unirían a la partícula viral ocultando la parte de la proteína S que interactúa con la ACE2, limitando efectivamente el número de células infectadas y desacelerando la propagación del virus.

Aunque el SARS-CoV-2 inicialmente infecta el tracto respiratorio y las células pulmonares, la proteína ACE2 se expresa en células del corazón, los riñones y el intestino. COVID-19 se describió inicialmente como una enfermedad respiratoria. Sin embargo, a medida que caracterizamos con mayor detalle las interacciones entre el virus y nuestras células a nivel molecular, descubrimos que esta enfermedad afecta a múltiples órganos y tipos de células. Para desarrollar terapias y vacunas efectivas contra el SARS-CoV-2, necesitamos comprender mejor los orígenes del virus, caracterizar la estructura de sus proteínas, la función de sus genes y comprender cómo causa enfermedad. Dibujar una imagen clara y completa del SARS-CoV-2 revelará sus fortalezas y debilidades y nos va a dar la información necesaria para diseñar terapias efectivas en el futuro. Como resultado de muchos años de ciencia básica, recientemente se han producido vacunas contra COVID19 que han demostrado ser seguras y eficaces para controlar la pandemia en tiempo récord. Por lo tanto, el apoyo a la investigación fundamental es y seguirá siendo crucial para garantizar el progreso científico en el futuro. 


\section{Contribuciones}

Frida Sommer escribió el artículo. Es editora científica y escritora científica independiente (https://www. vasocosmico.com/). Obtuvo su Ph.D. en inmunología por la Universidad de Leiden en los Países Bajos y tiene una maestría en ciencias arqueológicas por la Universidad de Durham. Sus intereses son muy diversos. (https://www.linkedin.com/in/fridasommer/)

Ernesto Llamas escribió/editó el artículo e hizo la ilustración. Actualmente es investigador postdoctoral en CECAD en Colonia, Alemania. Obtuvo su Ph.D. en Biotecnología por la Universidad de Barcelona realizando su investigación en el CRAG (Centre for Research in Agricultural Genomics). Creador, editor e ilustrador de Sketching Science. (Twitter @neto_flames; Instagram @eellamas).

\section{References}

The SARS coronavirus nucleocapsid protein - Forms and functions. (2014). Antiviral Research, 103, 39-50. https://doi.org/10.1016/j.antiviral.2013.12.009

Molecular Diagnosis of a Novel Coronavirus (2019-nCoV) Causing an Outbreak of Pneumonia. (2020). Clinical Chemistry, 66(4), 549-555. https://doi.org/10.1093/clinchem/hvaa029

Detection of 2019 novel coronavirus (2019-nCoV) by real-time RT-PCR. (2020). Eurosurveillance, 25(3). https://doi.org/10.2807/1560-7917.es.2020.25.3.2000045

Structural basis for the recognition of SARS-CoV-2 by full-length human ACE2.. (2020). Science, 367, $1444-1448$.

Structure of the SARS-CoV-2 spike receptor-binding domain bound to the ACE2 receptor. (2020). Nature, 581(7807), 215-220. https://doi.org/10.1038/s41586-020-2180-5

SARS-CoV-2 strategically mimics proteolytic activation of human ENaC. (2020). ELife, 9. https://doi. org/10.7554/elife.58603

Coronavirus biology and replication: implications for SARS-CoV-2.. (2020). Nat Rev Microbiol.

(2020). https://elpais.com/elpais/2020/03/06/ciencia/1583515780_532983.html. https: //elpais.com/elpais/2020/03/06/ciencia/1583515780_532983.html

https://www youtube. com/watch?v=5DGw0JXSxqg\&t=162s. https://www $\cdot$ youtube.com/watch?v= 5DGwOJXSxqg

Sahin, U., Karikó, K., \& Türeci, Ö. (2014). mRNA-based therapeutics - developing a new class of drugs. Nature Reviews Drug Discovery, 13(10), 759-780. https://doi.org/10.1038/nrd4278 